\title{
Input of creep and shrinkage characteristics for a structural analysis program
}

\author{
Z. P. Bazant
}

Active Member, RILEM; Professor of Civil Engineering and Director, Center for Concrete and Geomaterials, Technological Institute, Northwestern University, Evanston, Illinois, 60201, U.S.A.

Presented is a computer program for the input of creep and shrinkage properties for a structural analysis program. The program either accepts numerical data on the compliance function and the shrinkage function at discrete load durations and ages at loading, or uses the recent BP Model for creep involving the double-power law. The most useful characteristic is the availability of thirteen different options for specifying the creep and shrinkage parameters; sealed conditions or drying conditions, creep values specified and interpolation to be used, parameter of a creep formula specified, or creep formula automatically fitted to given creep data, short time data specified and extrapolation done by a formula, etc. In addition to returning the compliance function, the program also calculates the relaxation function and the age-dependent elastic moduli of a Maxwell chain model that is equivalent to the given creep properties. The program is particularly suitable for the input of creep characteristics for a large-scale finite element analysis.

\section{INTRODUCTION}

Development of numerical structural analysis methods for creep and shrinkage of concrete has greatly enhanced our capability of realistic modeling and prediction of structural behavior. Implementation of such an analysis however requires the use of a realistic model for creep and shrinkage properties (constitutive equation) and optimum adaptation of this model to available data on the material.

Extending the work briefly outlined in a recent conference paper [1], we present here a complete listing of a computer program which serves the aforementioned purpose. This program allows for characterizing the creep and shrinkage properties by a set of measured or given values at discrete times or by formulas recently presented in this Journal [2]. Various mixed modes of input, combining partial experimental data and automatic fitting of a formula are also available in this program. The most useful feature of the program is the availability of numerous options for the specification of creep (and shrinkage) properties by the user and for the type of representation of the compliance function. In addition to generating the compliance function, the program also automatically calculates discrete values of the relaxation function as well as discrete values of the age-dependent elastic moduli of a Maxwell-chain rheologic model - a model which allows the most efficient analysis of large structural systems by finite elements.

The FORTRAN IV listing which we present here includes numerous comments defining the meaning of 
principal variables as well as the input. The output of the program is also made self-explanatory by the headings and comments. It is therefore possible to understand and use this program without a separate guide, which could not be anyhow condensed into a short paper. However, a detailed guide is available [3], as part of a manual for a complete finite element program for concrete creep at variable temperature.

\section{CONSTITUTIVE RELATION}

The present program characterizes creep in terms of a compliance function $J\left(t, t^{\prime}\right)$ (also called creep function), which represents the strain at age $t$ caused by a unit constant stress acting since the age $t^{\prime}$.

By using this fonction, we assume the constitutive equation to be linear, obeying the principal of superposition [4]. The linearity assumption is acceptable only at stresses less than about one-half of the strength of concrete. One must be aware, however, that even within this range significant deviations from linearity are observed upon sudden unloading and generally in regimes of decreasing strains. Further significant deviations from linearity are caused by a drying simultaneous with creep, chiefly due to microcracking produced by the drying. By considering the compliance function as a function of two variables $\left(t, t^{\prime}\right)$, the aging of concrete is taken into account.

To facilitate the analysis of large structural systems, the program also generates the material parameters for a rate-type constitutive law for the aging creep of concrete. The well-known Maxwell chain model with age-dependent elastic moduli is chosen for this purpose ([5], [6]). This formulation allows the storage of the history of stresses or strains to be dispensed with, and thus it greatly reduces the computational costs and increases the size of the structural system that can be handled on a given computer.

\section{SIMPLIFIED FLOW CHART OF THE PROGRAM}

1. Read the number of decades in log-time scale to be considered, the number of steps per decade, the number of elements in Maxwell chain, the time for the start of the first time step, and the first relaxation time.

2. Read the input option number and the corresponding material data from which the characterization of the compliance function is developed. When the case of drying is specified, read also the characteristics for shrinkage and drying creep.

3. Compute the discrete values of the relaxation function for various strain durations and various ages at the start of relaxation. (This consists in a direct numerical solution of a linear Volterra integral equation.) (RELAX).
4. Compute the discrete values of the Maxwell chain moduli at all discrete ages (MAXWL 1).

5. As a check, compute discrete values of the compliance function from the discrete values of Maxwell chain moduli for various ages (CRCURV). Print the resulting values of the compliance function and of their deviations from the initially specified values of the compliance function. Also calculate and print the coefficient of variation of these deviations.

During the determination of the relaxation function, a subroutine for the compliance function is repeatedly called. This subroutine has three options to be specified by the user:

1. The compliance function is evaluated by interpolation from a given array of discrete values. The interpolation is linear in the logarithm of elapsed time and in the logarithm of the age at loading. For durations and ages falling outside the range, extrapolation is automatically used.

2. The compliance function is evaluated from a formula corresponding to the double power law [7].

3. If drying is specified, the compliance function is evaluated from a formula consisting of the double power law enhanced by a drying term [7].

The ultimate result obtained in the subroutine MATPAR is the array of discrete values of the moduli of the Maxwell chain. For any specified age, the values of the Maxwell chain moduli are computed (in subroutine function EMUF) from these discrete values by a linear interpolation in the logarithm of the age of concrete. For arguments falling outside the time range, a linear extrapolation from the two values at the end of the array is used.

\section{INPUT OPTIONS FOR MATERIAL CHARACTERIZATION}

In practical applications, many different situations can arise. Sometimes measured values of the creep function for many different times and ages at loading may be available, as is often the case in the design of nuclear structures. For other than special sensitive structures, the typical situation is that no measured creep data are available for the concrete to be used in the structure under design, and then some prediction formulas for creep and shrinkage need be employed, for which the BP model [2] is adopted here. Often, however, at least some experimental information may exist for the particular value of the elastic modulus, or even measured short-time creep deformations for one loading age or a few short load durations. Furthermore, even when full or partial experimental data may be available, they may be too scattered or uncertain, in which case a smoothing of the data by a realistic creep formula is appropriate. Similarly, the use of a creep formula is inevitable for the extrapolation of short-time creep data to long durations. 
To treat the various possibilities just outlined, the following options for the material characterization are provided in the program MATPAR:

1. The compliance function is specified as an array of discrete values for various load durations and various ages at loading. No drying is considered.

2. Drying is considered, and the mean compliance function for the cross section is specified as in option 1. Also, the values of the mean shrinkage strain of the cross section are specified for various durations of drying and the given age at the start of drying.

3. The compliance function is given by the double power law, for which all of its five parameters are read. No drying is considered.

4. Same as option 3 but all double power law parameters except the 28-day elastic modulus are generated from the given strength and composition parameters of concrete (the mix ratio of water, cement, sand and gravel, the cement type, and the unit weight of concrete).

5. Same as option 4 except that the 28 -day elastic modulus is also predicted from the strength and composition parameters.

6. Drying is specified and the compliance function is defined by the double power law enhanced by the term for the creep increase due to drying [2]. A formula for the shrinkage strain evolution in time (according to Ref. [2]) is also specified. And all parameters for these formulas are read.

7. Same as option 6 but all material parameters except the 28-day elastic modulus and the final shrinkage strain are predicted from the strength and the composition parameters of concrete (and also from the given ambient humidity).

8. Same as 6 but all parameters except the 28-day elastic modulus are predicted from the strength and composition of concrete.

9. Same as option 6 but all parameters are predicted from the strength and composition of concrete.

10. Two of the five double-power law parameters (namely, $E_{0}$ and $\varphi_{1}$, see Ref. [2]) are determined so as to obtain the best fit (in the least-square sense) of the given array of discrete values of the compliance function at various load durations and various ages. The remaining three double power law parameters are given. This option is used when the given array of discrete values for the compliance function is of limited range in time and/or age. No drying is considered in this option. As a check, the coefficient of variation for the deviations of the formula from the given limited array of values for the compliance function is automatically computed and printed.

11. Same as option 10 but the remaining three double power law parameters are not specified; they are predicted from given strength and composition of concrete.

12. Same as option 10 but drying is considered.
13. Same as option 11 but drying is considered.

The user selects his input option depending on the amount of information available to him before the analysis. If sufficient test data have been obtained, as is frequently done for nuclear concrete structures, then the measured discrete values of the compliance function should be used. However, if the range of these available data is too limited, it is preferable to approximate these values by the double power law.

If no experimental information is available, the double power law parameters are predicted from the strength and composition of concrete. However, if there exists some information on the double law parameters for a similar concrete, an adjustment of some of its parameters is appropriate. Moreover, if the shorttime deformation (elastic modulus) is measured, it should be also used to improve the parameters of the double power law.

The choice of the proper input option has a great effect on the accuracy in representing the concrete properties.

\section{OUTPUT AND APPLICATION}

The ultimate result of the program is the subroutine EMUF which generates the values of the Maxwell chain moduli, and in case that drying is specified, also the subroutine SHRINK which generates the values of the mean shrinkage strain of the cross section. Subroutine EMUF may then be called from a structural analysis program performing a step-by-step numerical solution.

As an alternative in case of a structural system that does not involve too many degrees of freedom, one may prefer characterizing the creep properties in terms of the compliance function $J\left(t, t^{\prime}\right)$ and performing the structural analysis on the basis of the principle of superposition, which leads to integral equations in time. In that case, subroutines RELAX, MAXWL 1, CRCURV, and EMUF can be discarded and the calls for these subroutines eliminated from the main program MATPAR.

\section{CONCLUDING REMARKS}

The present program would hopefully help increasing the accuracy of material representation in computer creep analysis. Available finite element programs make an accurate analysis of complex structures possible, but this possibility can be realized only if the material is characterized with a commensurate accuracy. It makes no sense to carry out a sophisticated finite element analysis and at the same time use some crude model for representing creep, a model of the type intended for hand calculations in a design office. In case of the analysis of concrete structures for creep and shrinkage, it is currently the material model which represents by 
far the greatest source of error. Thus, devoting more effort to material modeling than to the structural calculations has the greatest potential pay-off.

The salient feature of the present program is its adaptiveness to the amount of information supplied. If the user supplies very little information about his concrete, the program automatically predicts reasonable values of material parameters but the resulting prediction of creep is of course crude. Various options allow the user to supply more information with the advantage of better prediction of creep.

\section{ACKNOWLEDGMENT}

The coding of the program was carried out under subcontract No. 40-40434 V with Oak Ridge National Laboratory, Tennessee, operated by the Union Carbide Corporation for the U.S. Department of Energy. The mathematical models which are used in the program were previously developed under the sponsorship of the U.S. National Science Foundation (Grants GK-26030 and ENG75-14848). Thanks are due to Mehran Salehi for his help in debugging the program.

\section{REFERENCES}

[1] Bazant Z. P., Rossow E. C. - Finite element program for creep analysis of concrete structures, Transactions, 6th Int. Conf. on Structural Mech. in Reactor Technology, Paris, 1981, Paper H 3/4, North Holland, Amsterdam, 1981.

[2] Bazant Z. P., Panula L. - Practical prediction of timedependent deformations of concrete, Materials and Structures, Parts I and II: Vol. 11, No. 65, 1978, pp. 307-328; Parts III and IV: Vol. 11, No. 66, 1978, pp. 415-434; Parts V and VI: Vol. 12, No. 69, 1979, pp. 169-183.

[3] Bazant Z. P., Rossow E. C. - CREEP 80-Axisymmetric finite element program for creep analysis of aging concrete structures at variable temperatures, Report No. 81-8A, Bazant and Rossow, Engineering Consultants, to Oak Ridge National Laboratory, Tennessee (subcontract No. 40-40434 V), Kenilworth, August 1981.

[4] ASCE Task Committee on Finite Element Analysis of Reinforced Concrete Structures, Subcommittee 7, "TimeDependent Effects", Chapter VI in Report Finite element analysis of reinforced concrete structures, ASCE, New York, 1981.

[5] Bazant Z. P., Wu S. T. - Rate-type creep law of aging concrete based on Maxwell chain, Materials and Structures (RILEM), Vol. 7, No. 37, 1974, pp. 45-60.

[6] BAZANT Z. P. - Thermodynamics of solidifying or melting viscoelastic material, J. of Eng. Mech. div., ASCE, Vol. 105, No. EM 6, December 1979.

\section{RESUME}

Introduction des caractéristiques de fluage et de retrait dans un programme d'analyse structurale. - On présente l'informatisation des propriétés de fluage et de retrait qui entre dans un programme d'analyse structurale. Le programme soit accepte les données numériques de la fonction d'adaptation plastique et de la fonction de retrait pour des durées de chargement et des âges au chargement discrets, soit utilise le récent modèle de fluage BP à loi de double puissance. La caractéristique la plus utile est qu'on dispose de treize options différentes pour spécifier les paramètres de fluage et de retrait : conditions d'étanchéité ou conditions de séchage, valeurs spécifiées de fluage et interpolations, paramètres d'une formule spécifiée de fluage ou formules de fluage telles qu'elles donnent automatiquement les valeurs de fluage, valeurs spécifiées pour de courtes durées et extrapolations à partir d'une équation, etc. Outre qu'il restitue la fonction d'adaptation, le programme permet aussi de calculer la fonction de relaxation et les modules élastiques en relation avec l'âge d'un modèle $H N$ de Maxwell, soit l'équivalent des propriétés de fluage données. Le programme se prête particulièrement à l'introduction des caractéristiques de fluage pour une analyse par éléments finis à grande échelle. 


\section{APPENDIX-FORTRAN IV listing of program MATPAR *}

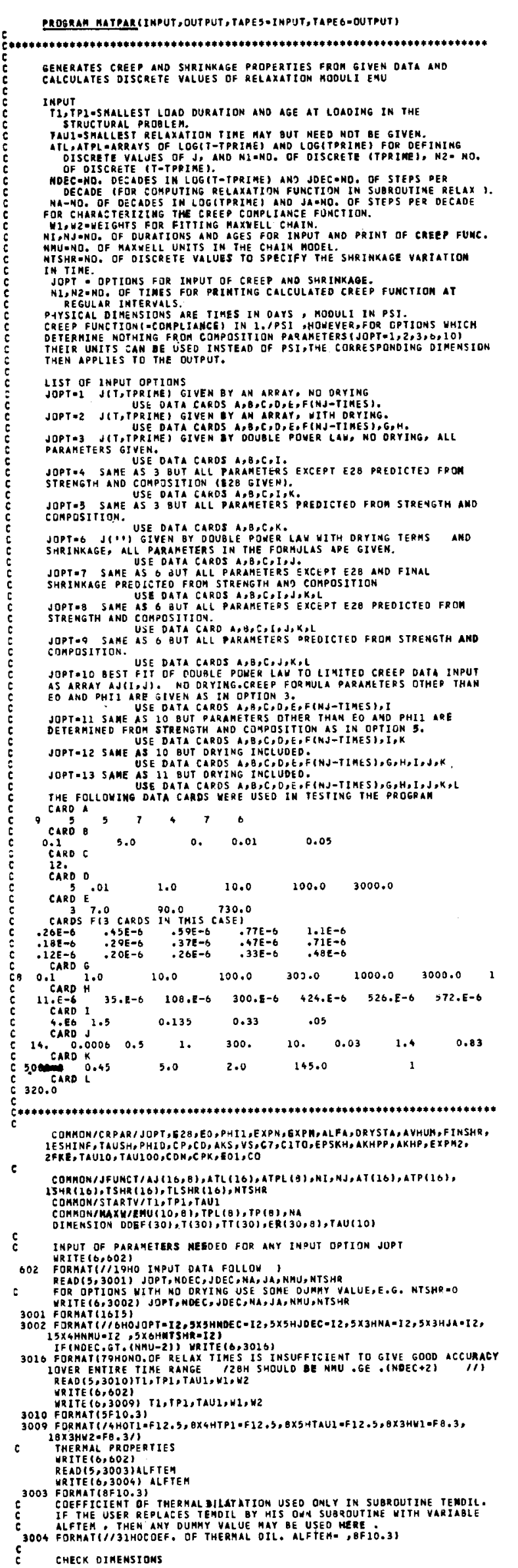

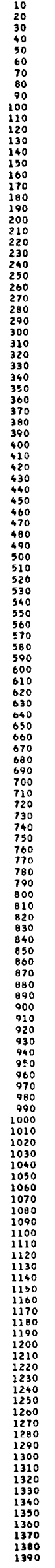

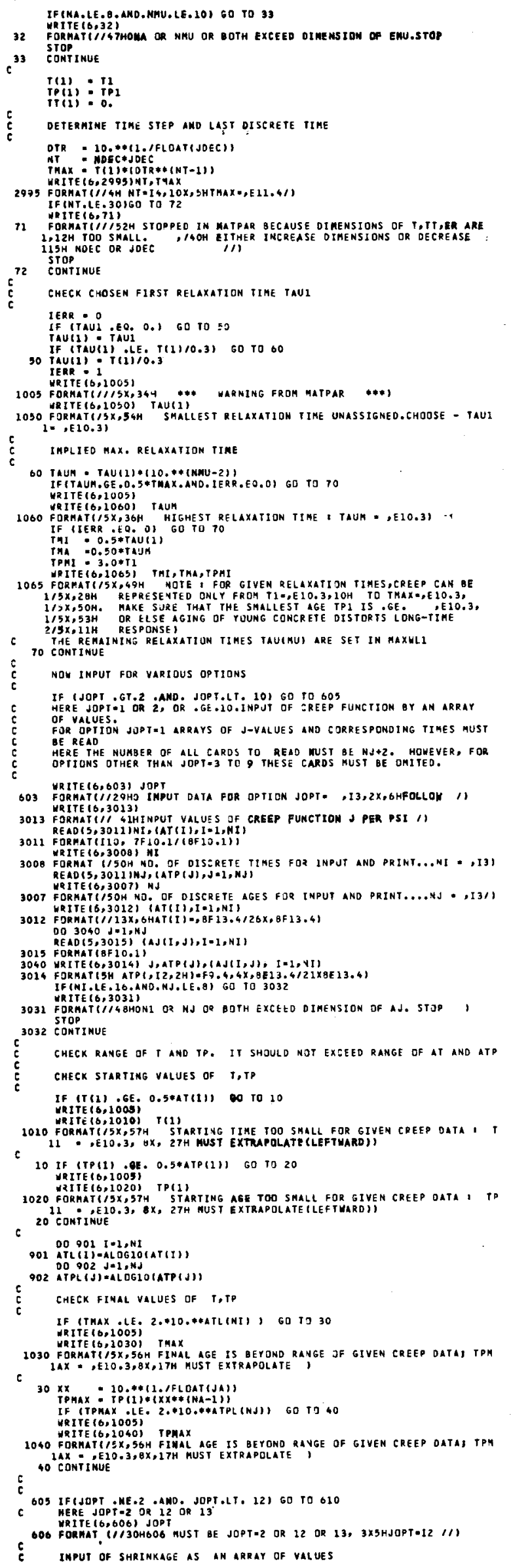

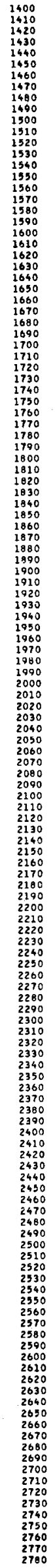

\footnotetext{
* Note that in all statements COMMON/CRPAR/the variable CITO contains the digit "zero", not the letter " 0 ".
} 
HR1TE $(6,603)$ JOPT REAO $(5,3100)$ NTSHR, (TSHR (I), $1-1, N T S H R)$
WRITE(6,3101) NTS TR, (TSHR(I), I=1,NTS TR)

3100 FORMATIIXI123H GIVEN SHRINKAGE VALUES, 3X, GHNTSHR, , I21113H IIMES

1OAYS) (OEET4.G)i

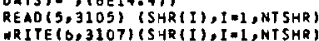

3105 FORMATCOE10.31

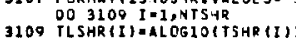

c

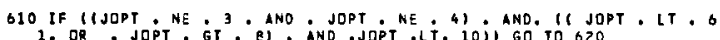

$c$
$c$ FOR JOPTE3,4,G,7,B,10,12 FUNCTION I IS DEFINEO BY DOUPLE POWER LAW AND ITS COEFFIGIENTS ARE SPECIFIED. TONEVER, FOR JOPT EEO. 10 OR

LATER REDEFINED, AND FOR JOPT=11 OR 13 PLACE A BLANK (DUMMYI CARD FOR JOPTE8 OR ? ONLY E2S IS NEEOEDANO THE REST CAN BE BLANK SINCE
IT IS LATER QEDEFINED BY INPUT FROM DATA GAROK NRITE (6,603)JJPT

C DATA INPUT For DOUGLE POWER LaW.

NOTE THAT DN DATA EARD THE EXPJJENT DF E-F JRMAT HUST gE RIGHT-

$R E A D(5,44 C 1)$ EZOE EOE 2Q, EXPN, EXPN, ALFA

4401 WORMAT 6,4402$)$ E 28 , EOE

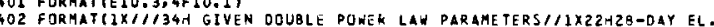
IMODULUS E2S=15.5,4H PSI115X, 6HECE28=,F9.4,5X,5HEXPN=F7.4,5X,

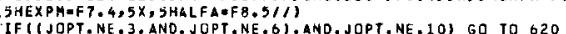
IF

PHII- (EOE28-1.1/(10.1**EXPN)*(28.**(-EXPM)+QLFA)

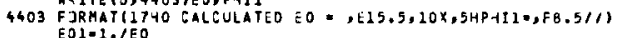
c

G20 IF(1JOPT.LT. O. OR. JTPT .GT, 9). ANO. JOPT.LT.15) GO TO 630

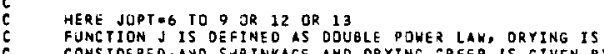

CONSIDERED,ANO SHRINKAGE AND ORYING GREEP IS GIVEN BY FOQYULA.

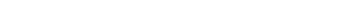

G23 FORMATI/137HB23 MUST IE JOPT=6 TO O OR 12 OR 13,3X,5HJUPT=12111 $c P=0$.

PAID:O.

AXS $=0$.

MRITE $(0,603)$ JOP

6 IF UNSURE ARIJUT INPUT OATA USE ZERUS JN THE aBOVE CARC.

THE FOLLONING AUTUMATIC ASSIGNYENTS AQE THEN MADE--.

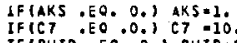

IF $(P H I D=E O, 0.1$ PHID 0.03

IF CCO EEO $0.1 \quad C D=1.4$
IF ICP $: E Q .0 .1 \quad C P=0.83$

C OPTIONS B AND 9-FUR CT,PHIO.CP AND EIYSSHR ANY OUMHY VALUES CAN $9 E$ USED SINCE THEY ARE LATER OETERMINED FROM COMPOSITICN.
FOR DPTION 7 THE SAME EXCEPT FINSHR IS NOT LATER REDEFINED.

TRITE 16,45021 DRYSTA, FINSHR, AVYUM, AKS, VS, C7, PHID, CD, CP

902 FORHAT $11 \times 1 / 155 \mathrm{H}$ GIVEN PARAMETERS FOR 5 HRINKAGE AND CREEP OUF IO DR HFINAL SHRINKAGE:

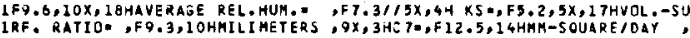

IIISX,

C 630 IF IJOPT .LT. \& JR. IJPPT EEQ.10 . OR. JOPT .EO. 611 GO TO 640

C PREDICT PARAMETERS OF DOUQLE POWER LAW WITHJUT ORYING TERNS FROM

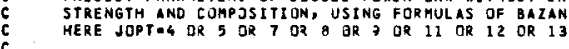

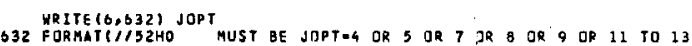
$1,3 x, 5 H D O P T=112111$

READ (S, B91) FCP, RE, AC, SC, RD, ITYPE
IRITE $(6, B 92)$ FCP, WC, AC, SC, RO, ITYPE

891 FORAATISF10.1, I10)
B92 FORMAT $112 X, 44 F C P=F 10.3,3 \times 3 H Y C=F 10.3,3 \times 3 H A C=F 10.3,5 \times 3 H S C=F 10.3$,

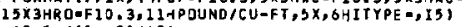

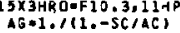

$A=1: 0$

IFITYPE EE. 3) A1-0.93

EXPM⿻0.28+1.1(FCPAFC

$x=(12.2 * A C) *(S C * *(-2.4) 1+10.1 * F C P * * 1.5) *(1 H C * * 0.3333333) * A G * * 2.2)$

IFIX

EXPN=0.12+0.07111, $+5130.1(x=6)$

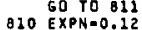

EXPN=0.12
$X=A L P A+28, * * 1-E X P M$

PHT1=10,3*11000,**EXPN)1/X

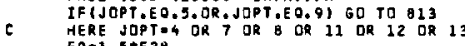

E0:1.5*E28

$823 \quad 21=(0.00003 *(R Q * R 0)) * F C P$

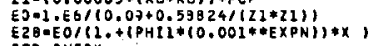

c FOR CHECK

$X=E O / E 28$
HRITE $(6,6709) X$

6789 FORMAT(1)1X,10H CHECK IF ,Fa.6,27H .NE.1.5 -ERROR- CORRECT IT II)

continue con

EO1-1.1EO

Q95 FORMAT 1158 SODOUBLE POHER LAN PARAMETERS PREDICTED FROM FCP ANO

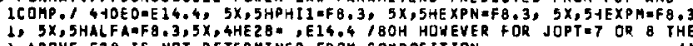

C6.0 IF IJOPT.LT, 7..OR. (JUPT .GT. Q .AND. JOPT . NE. 13) GO TO 650

MERE JOPTO OR OQ DR 9 OR 13
PREOICT PARAMETERS FOR SHRINKAGE AND DRYING CREEP FROM STRENGTH AMD COMPOSITION. DOUBLE POHER LAY PARAMETERS MUST ALREAOY $Q E$
643 FORKATLCOT35H JOPT

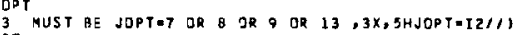
WRITE (6, 603) JOPT

TRITE $(0,714), C E$

713 FORMAT (1F 10.1)

c PARAMETERS FOR SHRINKAGE

CT=(0.125*WC)*CEM-12.

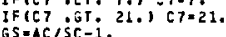

IF NOPT EE. ? GU TO 723

$(211.25 * S Q R T(A C)+0.5 *(G S * G S)) *((6(1)+S E) / W C) * * 0.33333333) *$ IFII

$r=1 .(390, * *(2 * *(-4))+1,1$
FINSHR $=(1210,-990, * Y) * 1, E-6$

FINSHR - $(12100-7800$

MRITE $(6,603)$ J JPT

112 FORMATI/IIOH CALCULATEO FINSHR., E13,4,10X,3HC7\%,E13,4,10X,3HGS.,

c parameters fur orying EREEP

$723 R=(56000, *$ (IFCP*(SC/AC) )**0.3))*(1GS**1.31*1(WC)/FINSHR*1.EQ U)

$1 * 1,511)-0.83$

IF TR LLE, O.) OS TC 715

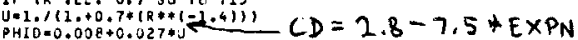

6010716
$5410=0.000$

716 CP $=0.83$

(19)

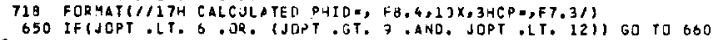

c MERE JOPT $=6$ JR 7 OR B DR 9 OR 12 OR 13

CALCULATE SHRINKAGE ANC CREEP PARAMETERS UF BAZART-PANULATS

FORAULAS (MATERIAL S E STRUCTURES, VQL.11,1978,P.30B).

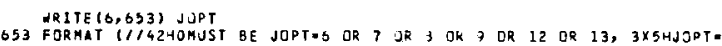

C1TO-C $7+1.05+5$ QRT $(6.3 /$ DRYSTA $) 1$

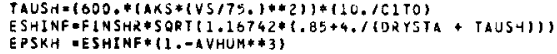

C Parameters fjo creep terms que to orying

AKHPP=1, -AVHUM

$A K H P=1,-A V H U M * * 1$.

FKE $=$ IAKTP $/ E$ TIKESHINF * I.E 6

TAU1O-10.*TAUSH
TAU100=100.TAUSH

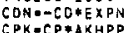

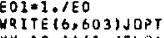

$X X=10 . * *(1 ., E$ UUAT(JA)

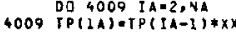

OTR $10, * *(1, F E$ TSATI JOEC)

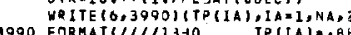

TP(IA):,BE12.3/\{13X,8E12.3\})

$\$ 000$ FORMATI/70HOEREEP FUNCTION VALUES INTERPDLATED FROM GIVEN DISCRET

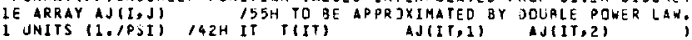

DU4020 IT:I, YT

4010 DDEFITA) CREEPIIIIT),TP(IAI)

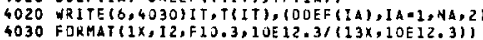

ORITE 60,657$)$ CITO. TAUSH, ESHINF, EPSKH, AKHPP, AKHP, GON, CPK

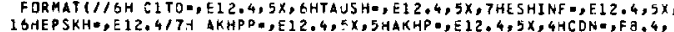
$15 X, 4 H C P K=, F B, 4)$
IF(JOPT, LT. 10$)$ GO TO 670

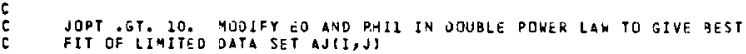

NRITE $(6,603)$ JJOT

EQ1=1:

$12=0$.
$122=0$.

$B 200$.

$A 11 \cdot \mathrm{NI} * \mathrm{~N} J$

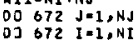

SEPB(AT(I), 4 TP(J)) $=1$

YFAJII,J)

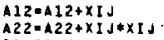

$B 1=B 1+Y$
$0 Z=B 2+Y+X I J$

672 $8 z-B z+Y * x I J$

DET-A11*A22-A12*A12

EO=1, 1 EOI

PHIJ-EO*(IA11*B2-A12*B1)/OET

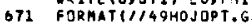

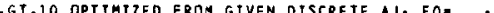

TE15.5, 5X,
670 COMTINUE

c PRESCRIBED STRAIN INCREMENTS FOR RELAKATIJN

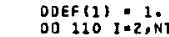

110 DDEF (II) 0 .

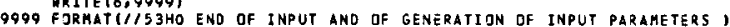

compute oiscrete values er of the relaxation function

CALL RELAX (NOEC, JDEC, JA, DOEF,T,TT,NT,ER)

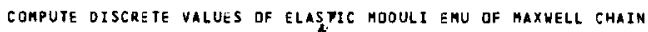

CALL MAXWLIER,T,TT,NT,WB,HZ,TAU, NMU)

IN DEBUGgING ARGUHENT NDEC AND JDEC AFTER TPL IN MAXWLI WERE

CHE CK AGAin LATER.

MRITE $(6,1100)$ (TAUTMU), MUEI, NMU)

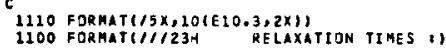




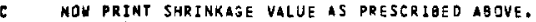

IF(JUPT IT POSTIOP

2415 FORMATSI/3 WOOPRINT SHRINKAGES VALUES AS PRESCRIBED /

44 $x$, 9HAGE (DAYS), $11 X$, BHS TRAIN 11

DO $1420 I T=1, N T+D R Y S T A$

B2-SHRINK(AZ)

1420 KRITE $(6,1425) 42, B 2$
1423 FURMAT(1X, 39X,Fi2, $2,5 X, F 12,6)$

STOP

FUNCTION CREEP $(X, Y)$

COHAON/TRPAR/JOPT, E 28,EO,PHII, EXPN, EXPH, ALFA, DRYSTA, AYHUM, FINSHR IESHINF ORAUSH, PHIO, CP, CO, AKS, VS, C7, C1TO,EPSKH, AKHPP, AKHP, EXPMZ,

IFIJOPT GT, 21 GO TO 10

RETURN. $\operatorname{CREEPB}(x, y)$

10 CREEP
RETUAN
END

BUNCTION CREEPA $(X, Y)$

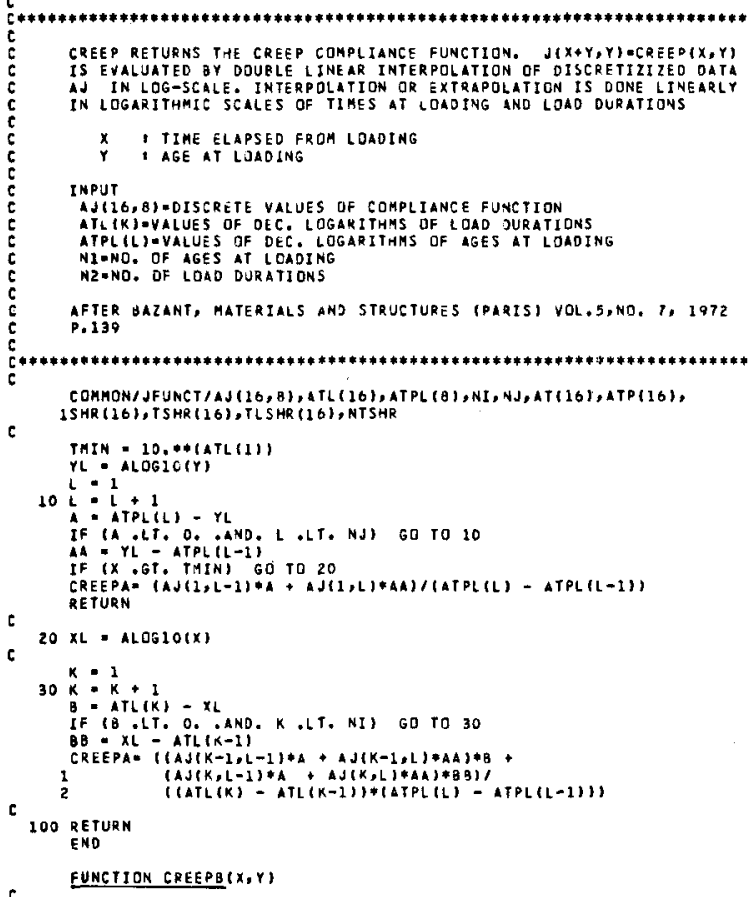

CUMCTION CREEPB $(x, x)$

DETERMINES CREEP FUNCTION J FROM DDUBLE PJAER LAW WITHOUT OR WITH ORYIMG TERMS.

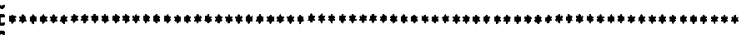

COMMON/CRPAR/JOPT, E28,EO,P411, EXPN, EXPM, ALFA, ORYSTA, AVHUH, FINSTR, LESHINF,TAUSH, PHID,CP,CD, AKS, VS, CT, CITO, EPSKH, AKHPP, AKHP, EXPMZ,

IF(JOPT . LT. 3) MRITE $(6,99)$ JOPT

6 DOUBLE POHER LAN GAZANT-PANULA, MATERIALS AND STRUGTURES, 1978

ADD THE DRYING TERMS
IF IJOPT .GT. S.AND. (JOPT .NE. 10 . ANO, JJPT .NE. 111) CREEPQE LCREEPB+DRTERM $(X, Y)$ RETURN

FUNCTION ORTERM $(X, Y)$

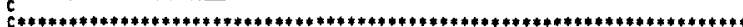

C Calculate orying term ti be adeed to double power lay.

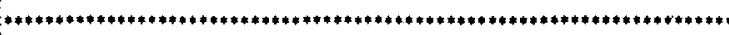

COMMON/CRPAR/JOPT, E28, EO,PHII, EXPN, EXPM, ALFA, ORYSTA, AVHUH, FINSTR, IESHINF,TAUSH, PHID, CP, CO, AKS, VS, CY

PHIDP1=SORT(1.+(Y-ORYSTA)/TAUIO) /PHID

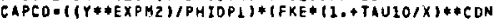

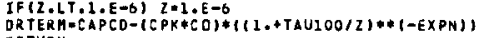

RETUR

FUNCTION SHRINK(T)

C******************************************************************

COMPUTES THE SHRINKAGE STRAIN FOR GIVEN DRYING DURATION T.

C*********************************************************+**********

COMMON/CRPAR/ SOPT, E 28, EO,PHII, EXPN, EXPN, ALFA, ORYSTA, AVHUM, FINSHR, LESHINF, TAUSH, PHIO, CP, CD, AKS, VS, C7, CITD,EPSKH, AKHPP, AKHP, EXPMZ,

C IFICJOPT AEQ. 21.0R.1JOPT.GT.111,GO IO 10

IF (JOPT . LT. 6 , OR, JOPT, EO, 10) KRTTE $(6,11)$ JOPT RELAX COAPUTES STRESS RESPONSE TO A OIVEN STRAIN HISTORY
IN GEEREA GNO DISCRETE VALUES ER OF. THE RELAXATION FUNCTION

FUNCTION CREEP(X,Y) MUST BE SUPPLIEU, CREEP(X,Y)=CCMPLIANCE FUNE-

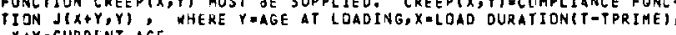
CAUTION... NOTE THAT IN SOME uTHER Programs argument

NOEC ND. OF DECADES DF TIME IN LOG-SCALE

DDEC-NO. OF STEPS PER LOG

JA-NO. OF AGES PER LOG(10)

TP(I)PFIRS AGE AT LOADING

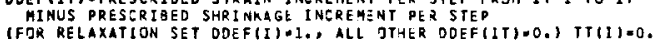

Dutpur

ER(IT, IAA DOISCREEE VQLUES OF RELAXAIIDN FUNCTION

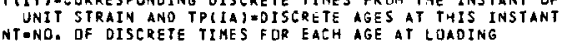

OIMENSIONS MUST de AT LEAST DSTR(NT), JDEF(NT), TINT), TT(NT), APINAI,

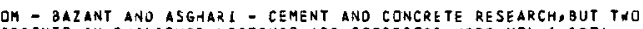

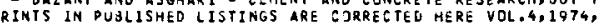
. $57-579$.

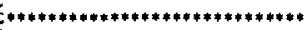

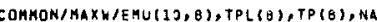

OIMENSION DOEF $(30), T(30)$, TT (30), ER $(30,5)$, DSTR (30)

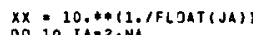

TP(IA)

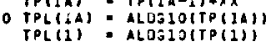

OTR : 10.**:11.,FLJATIJOEC)

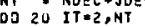

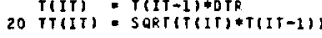

WRITE $(6,2000)$ (TOCIA), IAFI;NA)

DO 50 IA I I, NA

compute the first stress Value using Effective modulus.

OSTR(1)
ER(1,IA): DOEF(1)/CREEP(TI1), DP(IA)

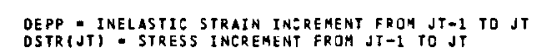

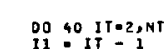

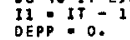

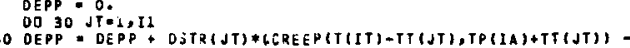

ACREEP(T(BH)-TT(JT),TP(IA)+TT(JT))

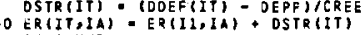

WRITE $(6,1010)$

c $0060 \mathrm{Tt}=1, \mathrm{HI}$

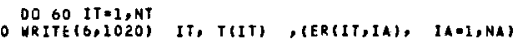

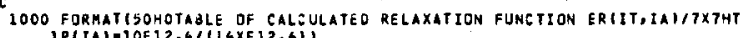

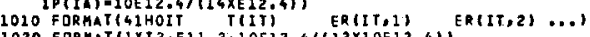

100 RETURN

SUBROUTINE MaXUL1IER,T,TI,NT, H1, H2, TAU, NMUS

E*************************************************************

MAXYLI EOMPUTES RELAXATION SPEETRA (VALUES OF EEASTIC MODUL EMU 


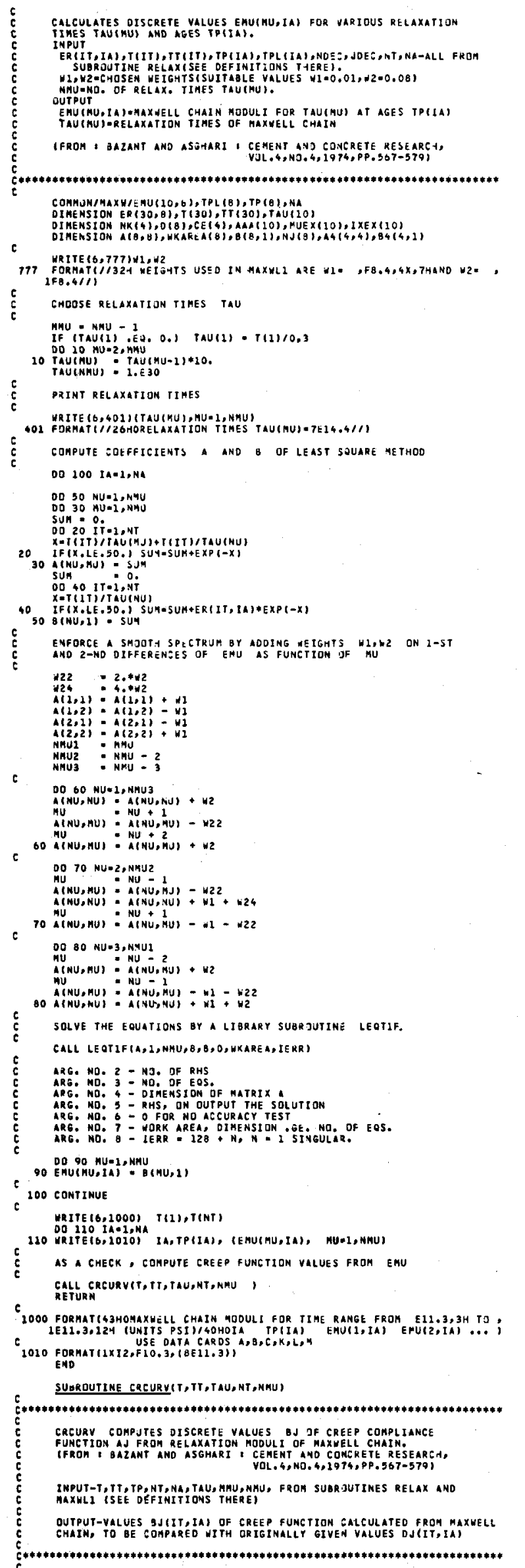

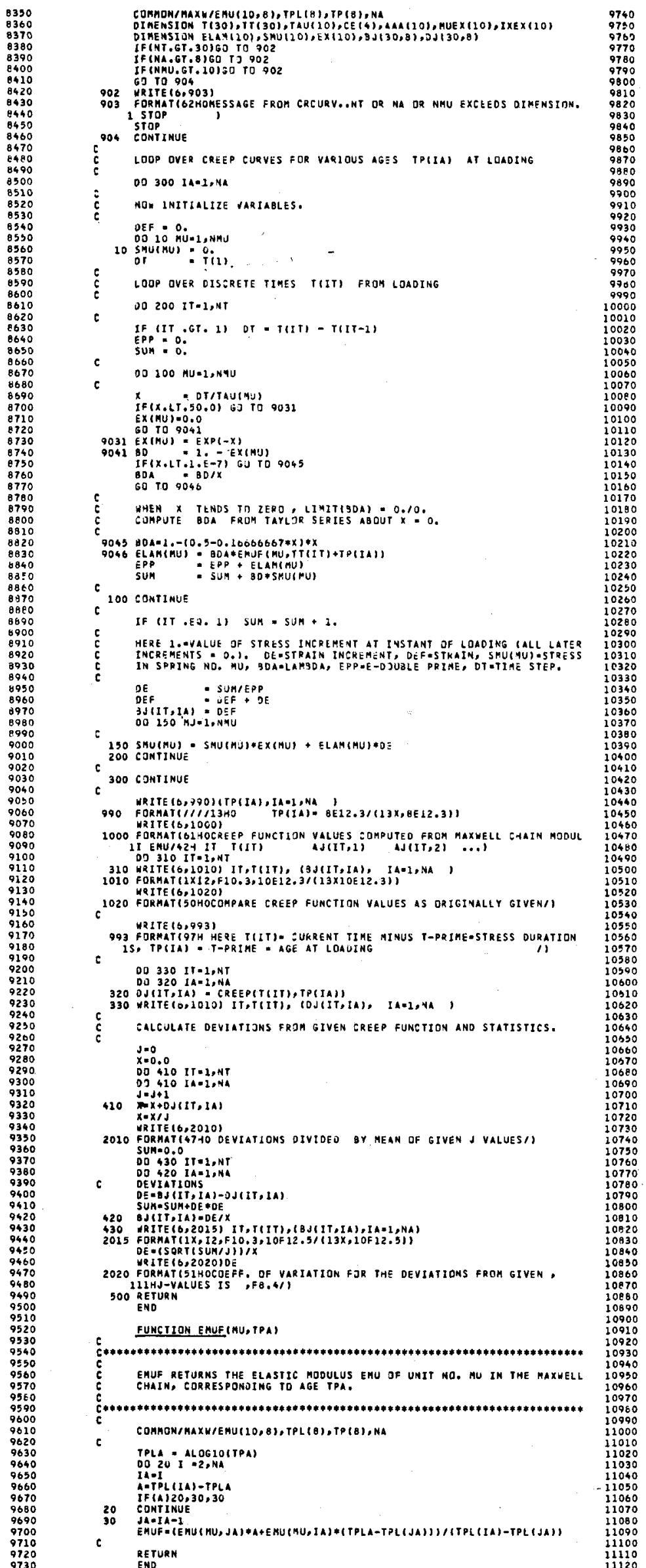

